Julia Maria Erber-Schropp

\title{
Schuld und Strafe
}

Eine strafrechtsphilosophische Untersuchung des Schuldprinzips

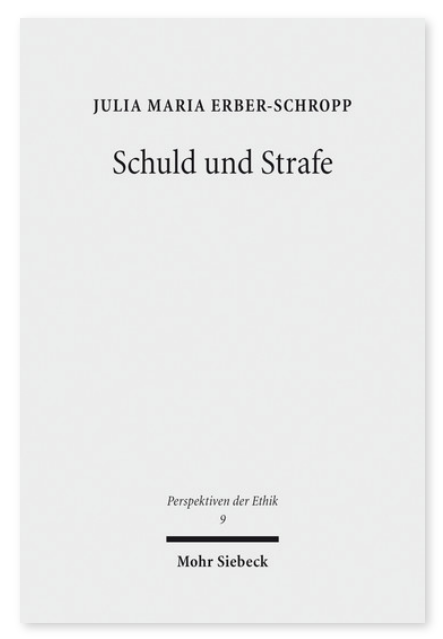

2016. X, 201 Seiten. PE 9

ISBN 978-3-16-154379-1

DOI 10.1628/978-3-16-154379-1

eBook PDF 59,00€

ISBN 978-3-16-153993-0

fadengeheftete Broschur 59,00€
Das strafrechtliche Schuldprinzip, also das Zusprechen von persönlicher Schuld im richterlichen Urteil zur Legitimation der Strafsanktion, ist ein vieldiskutiertes und umstrittenes Thema innerhalb der Strafrechtswissenschaft. Im Kontext der Diskussion um die Frage nach der Freiheit des Willens, die von manchen als Voraussetzung für Schuldfähigkeit angesehen wird, ist das Thema auch für die Philosophie von Relevanz.

Kritiker betrachten das Schuldprinzip als irreführend und ineffektiv für die Legitimation von Strafe. Sie fordern die Umgestaltung des Schuldstrafrechts zu einem Maßregelrecht, das auf die Bedürfnisse der gesellschaftlichen

Kriminalprävention ausgerichtet ist. Julia Maria Erber-Schropp zeigt, weshalb das Schuldprinzip eine elementare Bedeutung im Strafrecht hat und dass dieses nicht durch die Willensfreiheitsdebatte angreifbar ist.

Julia Maria Erber-Schropp Geboren 1978; 1999-2001 Studium der Kulturwissenschaften und Ästhetischen Kommunikation; 2001-06 Studium der Kulturwissenschaft und der Philosophie; 2003-04 Studium der Philosophie und der European Studies; seit 2007 Wissenschaftliche Mitarbeiterin der Stiftung Wissen der Sparkasse KölnBonn, seit 2013 Wissenschaftliche Leiterin; 2014 Promotion.

Jetzt bestellen:

https://mohrsiebeck.com/buch/schuld-und-strafe-9783161543791?no_cache=1

order@mohrsiebeck.com

Telefon: +49 (0)7071-923-17

Telefax: $+49(0) 7071-51104$ 